Int. J. Curr. Res. Med. Sci. (2017). 3(3): 83-93

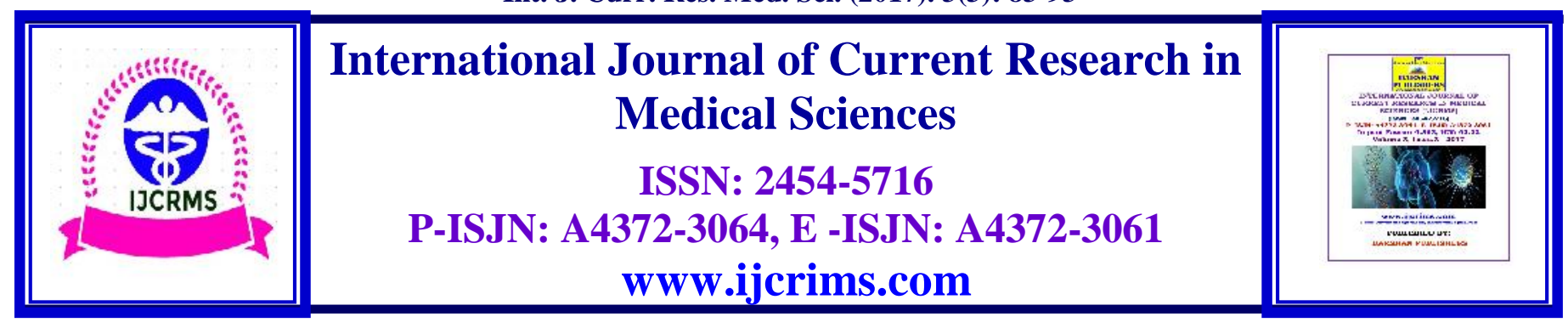

\title{
Cross sectional study to evaluate rapid diagnostic test (Typhidot-M) as a tool for early diagnosis of Typhoid fever keeping blood culture as gold standard.
}

\author{
Dr Neeraj Lata ${ }^{1}$, Dr Vijay Gotwal ${ }^{2}$, DR. Tanushree Joshi ${ }^{3}$, DR. YogeshGupta ${ }^{4}$, \\ DR. D P Pande ${ }^{5}$, Dr BrahmPrakash ${ }^{6}$ \\ ${ }^{1}$ Senior Resident, Department of Pediatrics, Government Medical College, Amritsar \\ ${ }^{2}$ Junior Resident, Department of Chest and Tuberculosis, Government Medical College, Amritsar \\ ${ }^{3}$ MD Pediatrics , ADMO (Pediatrics), Northern Railways Central Hospital Basant Lane, New Delhi \\ ${ }^{4}$ DCH, MD Pediatrics, Head of Department of Pediatrics ,Northern Railways Central Hospital ,Basant Lane, \\ New Delhi \\ ${ }^{5}$ DCH,DNB Pediatrics, Chief Pediatrician Northern Railways Central Northern Railways Central Hospital , \\ Basant Lane, New Delhi \\ ${ }^{6}$ DCH,PG DIP HA,Phd(Med), Medical Director, Northern Railways Central Northern Railways Central \\ Hospital , Basant Lane, New Delhi \\ Corresponding Author: Dr Neeraj Lata \\ E-mail: neerajlatavijay@gmail.com
}

\begin{abstract}
Introduction: Typhoid fever is highly prevalent in India with hight rate of morbidity and mortality. There is paucity of data from India for its rapid detection by Rapid diagnostic test like Typhidot-M. Thus this study has been taken up to study the use of rapid diagnostic test for typhoid fever keeping blood culture test as gold standard.

Materials and Methods : This cross sectional study was carried out in the Department of Pediatrics, Northern Railways Central Hospital, New Delhi. Blood samples of 100 patients with fever of more than 3 days duration were tested by Typhidot-M, Blood culture and S.Widal .S.Widal being done in second week of illness. Other tests for evaluation of other causes of fever were also done..

Results: Sensitivity and Specificity of Typhidot- M was found to be $97.8 \%$ and $46.3 \%$.Positive and Negative predictive values for this test were $60.8 \%$ and $96.2 \%$.Typhidot-M had better sensitivity and specificity than serum widal test.The association between blood culture positivity and Typhidot-M test was found to be highly significant statistically.

Conclusion: We concluded that there was significant association between blood culture positivity and Typhidot -M test in our study thus we can recommend Typhidot $-\mathrm{M}$ as the rapid, accurate and reliable tool for the early diagnosis of typhoid fever .
\end{abstract}

Keywords: Typhidot-M ,Typhoid fever, Blood culture 


\section{Introduction}

Typhoid fever continues to be a global health problem, especially in tropics and subtropics. ${ }^{1}$ Typhoid fever, also called enteric fever is caused by the facultative intracellular organisms salmonella, enteric serotype typhi(S.typhi)and salmonella paratyphi.Human beings become infected with S.typhi through ingestion of faecal contaminated food, milk or water. Therefore global distribution of the disease is limited to areas with poor standards of hygiene and sanitation which facilitate its transmission. ${ }^{2}$

Confirmed case of typhoid fever is defined, according to the World Health Organization (WHO), as a patient with fever $\left(>38^{\circ} \mathrm{C}\right)$ that has lasted for at least three days, with a laboratory confirmed positive culture of S. typhi. ${ }^{3}$

Probable case of typhoid fever is a patient with fever $\left(>38^{\circ} \mathrm{C}\right)$ that has lasted for $>3$ days, with a positive serodiagnosis or antigen detection test but without S. typhi isolation. ${ }^{3}$

Enteric fever is endemic in India with a rate of incidence ranging from 102 to 2219 per 100,000 in the population. ${ }^{4}$

An incidence of 980/100000 was recorded in late 1990 's in a five year community based study of children in Delhi. ${ }^{5}$

According to the best global estimates there are at least 17 million new cases of typhoid fever each year, with 600,000 deaths. ${ }^{7}$ Reported data by GOI for year2005shows 653580 cases and 417 deaths of typhoid fever. ${ }^{2}$

History, physical findings and fever pattern are suggestive but can neither confirm nor exclude typhoid. ${ }^{4}$ One has to rely on serological diagnosis since many diagnostic laboratories in developing countries do not have facilities for blood culture. ${ }^{6}$

Blood culture is generally recognized as the most useful diagnostic test for detecting S.typhi. However, a single blood culture is estimated to be only $50 \%$ to $80 \%$ sensitive and the delay from specimen collection to diagnosis can be 5 to 7 days ${ }^{7}$. Moreover, blood culture is prohibitively expensive in most settings where typhoid fever is endemic.Serodiagnosis of typhoid fever has been attempted since 19th century when Widal and Sicard showed that serum of patients with typhoid fever agglutinate typhoid bacilli. ${ }^{8}$

Therefore, diagnosis and treatment of typhoid fever in endemic and resource-constrained settings is commonly done on the basis of clinical presentation or a positive Widal test, which has suboptimal sensitivity and specificity ${ }^{9-11}$.Isolation of serotype type from blood remains the method of choice for the laboratory diagnosis. Widal test is the mainstay in the diagnosis of typhoid fever in most laboratories but it has drawbacks $9,10,12$

Thus there is a pressing need to develop more reliable user-friendly rapid diagnostic assays for typhoid fever.

As signs and symptoms of typhoid fever are nonspecific, the isolation of the organism from blood, bone marrow, or stool is required to confirm the diagnosis. Isolation of the organism from blood requires 5 to $10 \mathrm{~mL}$ of blood, 2 to 7 days' time, elaborate laboratory equipment, and a level of technical expertise, which may not be present in resource-poor laboratories. Even under the best conditions, there may be failure to isolate the organism, especially after antimicrobial treatment has been started. Culture of bone marrow is more sensitive, but the procedure is invasive ${ }^{13}$. Rapid dot enzyme immunoassays have been tested and are being used widely over the world from few years with varied result. Test is based on the presence of specific IgM antibodies to a specific $50 \mathrm{kD}$ outer membrane protein (OMP) antigen on S.typhi and becomes positive as early as in the first week of the fever. The results can be interpreted visually and is available within three hours. ${ }^{14,15}$

Rapid accurate diagnosis and early treatment with suitable antimicrobials is essential for speedy recovery and for prevention of complications and deaths due to this disease. 
The emergence of multidrug-resistant strains of salmonella typhi is known to be associated with significant morbidity and mortality. Its a well recognized fact that a delay in diagnosis and institution of appropriate therapy may significantly increase the risk of adverse outcome and mortality. ${ }^{10}$

The disease is predominantly a disease of school going children and young adults and is reported to be milder in infants and young children . ${ }^{16}$

This study has been taken up with the objective to evaluate the sensitivity and specificity of the Typhidot -M assay while keeping blood culture positivity as a gold standard. Panel of tests were done to rule out other causes of fever.

This study will help to diagnose typhoid fever at the earliest thus preventing the complications. Paucity of data in India on rapid diagnostic tests for detecting typhoid fever at earliest, led us to study this issue in a cross section of population of patients attending Northern Railway Central Hospital.

\section{Materials and Methods}

The present study was a hospital based crosssectional study. The study was carried out in the Department of Pediatrics, Northern Railways Central Hospital, New Delhi. Parents of patients were told about the nature of study and informed consent was taken. Ethics committee clearance was taken for study.

\section{Inclusion criteria}

1. Age:1-14yrs

2. Both sexes

3. Both Indoor and outdoor patients

4. Duration of fever of more $>3$ days.

5. Fever $>380 \mathrm{C}$

\section{Exclusion criteria}

1. Previously antibiotic treated patients.

2. Proven localized infection.

\section{Sample size:}

100 patients from opd and indoor admission with fever of greater than 3 days duration were included in the study. Typhidot-M test,Serum Widal, Blood culture and other panel of tests for fever were sent. Other panel of tests like hemogram ,ESR,Periferal smear for malarial parasite ,Indirect coombs test for plasmodium vivax and falciparum, Liver function and kidney function tests were done. Serum widal was sent in $2^{\text {nd }}$ week of fever by tube method.

\section{Test details}

1.Typhidot-M Test (ENTEROCHECK-WB by Zephyr Biomedicals)

Principle: This is a rapid, qualitative, sandwich immunoassay for the detection of $\operatorname{IgM}$ antibodies to $\mathrm{S}$. typhi in human serum/plasma or whole blood specimen. Early rising antibodies to Lypopolysaccharide (LPS) O are predominantly $\operatorname{IgM}$ in nature. Detection of S. typhi specific IgM antibodies instead of IgG or both IgG \& IgM (as measured by the Widal test) would serve as a marker for recent infection, qualitatively detects the presence of IgM class of Lypopolysaccharide (LPS) specific to S. typhi in human serum/plasma or whole blood specimens.It utilizes the principle of Immunochromatography, a unique two-site immunoassay on a nitrocellulose membrane.

\section{Testing procedure and interpretation of} results:

The kit components of device have to be brought to room temperature before testing. Once opened, the device must be used immediately. Place the testing device on a flat horizontal surface.Dispense 51 of whole blood / serum / plasma into the specimen port ' $A$ ' using a micropipette or the sample loop provided. Dip the sample loop in the sample container and blot the sample in the sample port 'A'. Add five drops of sample running buffer into the reagent port ' $\mathrm{B}$ '. At the end of 15 minutes, read results as follows: 
If IgM antibodies to S.typhi are not present, only one coloured band appears in the Control Window (C). If IgM antibodies to S.typhi are present, two coloured bands appear in the Test (T) and Control Windows (C). The test is invalid if the Control band is not visible at fifteen minutes.

\section{Blood culture(BACT/ALERT- PF)}

These culture bottles were used with BacT/ALERT Microbial Detection System.Its a quantitative procedure for enhanced recovery and detection of bacteria(aerobic and facultative anaerobic ) from blood.

\section{Principle of the test}

The method utilizes a colorimetric sensor and reflected light to monitor the presence and production of carbondioxide dissolved in the culture medium.If microorganisms are present in the test, carbondioxide is produced as the organisms metabolize the substrates in the culture medium. When growth of the microorganisms produces $\mathrm{CO} 2$, the color of the gas permeable sensor installed in the bottom of the each culture bottle changes from blue green to yellow. The lighter color results in an increase of reflectance units monitored by the system. Bottle reflectance is monitored and recorded by the instrument every 10 minutes.

\section{Specimen collection and preparation}

Proper skin disinfection is an essential requirement to reduce the incidence of contamination. Upto $4 \mathrm{ml}$ of sample obtained and transferred to the bottle under aseptic precautions.In the laboratory blood culture bottles were incubated at $37^{\circ} \mathrm{C}$ and checked for growth at1,2,3, and 7 days.For days1,2and 3,only bottles showing signs of positive growth were cultured on agar plates.On day 7 all bottles were subcultured before being discarded as negative. ${ }^{24}$

After bact-alert (blood culture )positivity for growth of bacteria,subcultures were done. ${ }^{21}$ On blood agar,S.typhi and S.paratyphi produce non hemolytic smooth white colonies.On MacConkey agar,Salmonella produces lactose non fermenting smooth colonies..Biochemical tests were done to diagnose growth of salmonella typhi by recommended standard protocol.

\section{Aims and Objectives}

To determine the sensitivity and specificity of rapid diagnostic test (Typhidot-M) as a tool for early diagnosis of typhoid fever keeping Blood Culture as gold standard.

\section{Results}

Demographic, clinical data, laboratoryParameter details were noted and analysed using SPSSsoftware version 17(SPSS Inc., Chicago, IL, USA).

In our study Male to female ratio is 1.3:1 . Males were more affected than females.

Patients in age group 5-8yrs were maximally affected by typhoid fever followed by $9-12$ yr age group.

In our study age ranged from 1.5 yrs to14 yrs with mean age of $8.2 \mathrm{yrs}+/-3.3 \mathrm{SD}$.

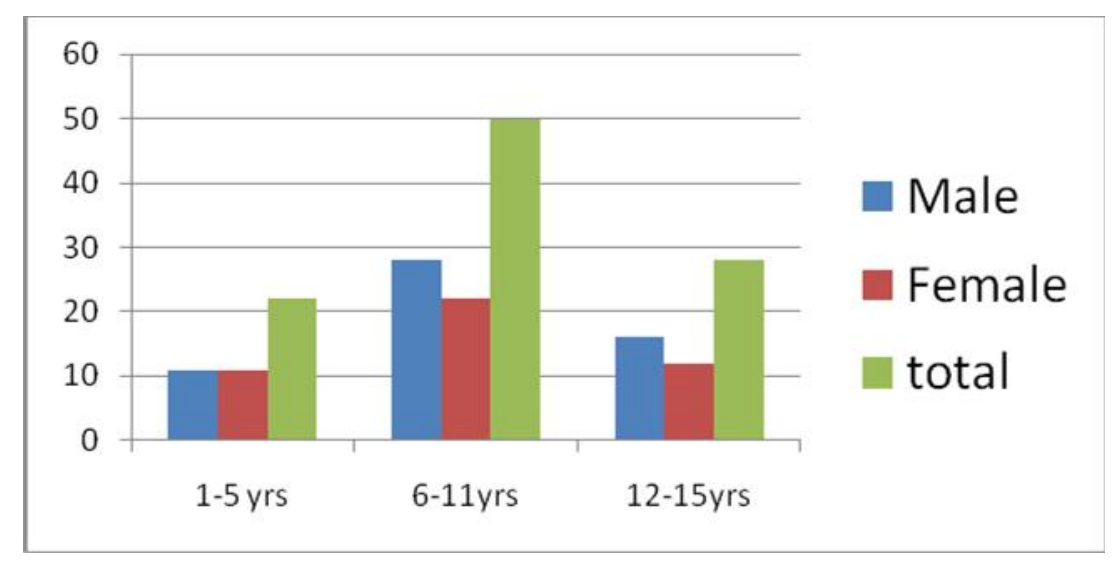

Fig 1.Age distribution of cases. 
Int. J. Curr. Res. Med. Sci. (2017). 3(3): 83-93

Age group 6-11 years was affected most. 50\% of patients belonged to this group .In this age group males were affected more than the females

In our study population of 100 patients, 46 were having blood culture positivity for S.typhi .When we compared blood culture results in both genders , blood culture positivity in male gender was found to be statistically significant $(p<0.05)$

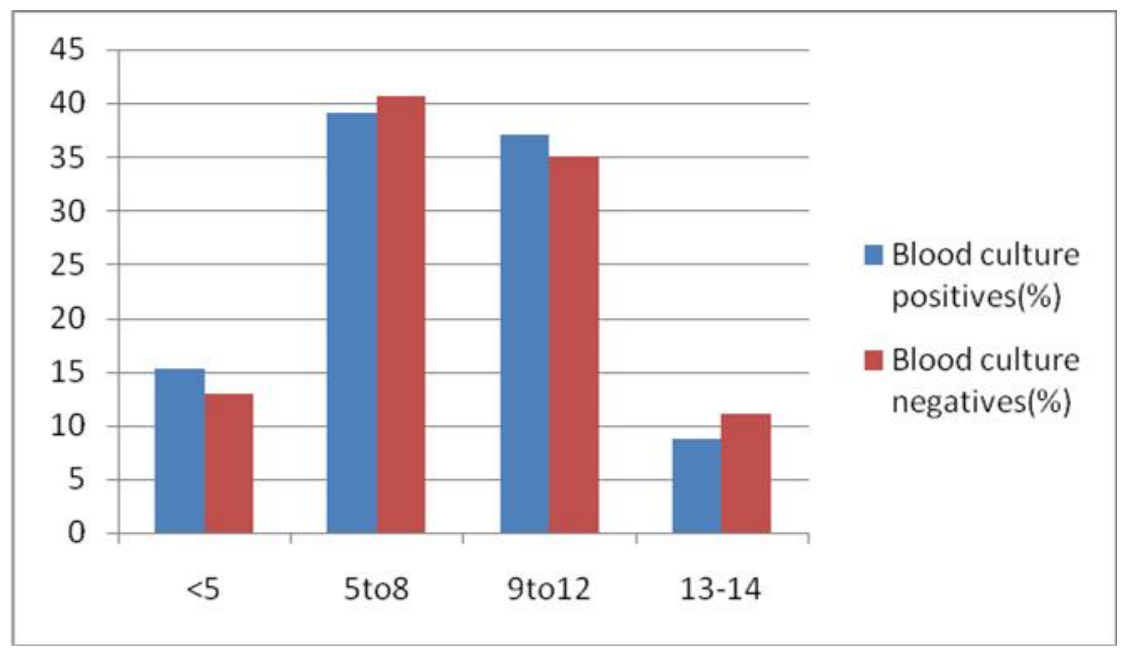

Fig 2. Distribution of Blood culture(\%) results in various age groups.

When we plotted the distribution of Blood culture results in various age groups, maximum positivity was seen in age group 5-8yrs followed by $9-12$ yrs.

Comparison of blood culture results in various age groups found that there was no statistical significance( $p>.05)$.

Blood culture positivity ranged from 1.5 yrs to 14 yrs with mean age 7.880+-3.24SD and its association with age distribution was found to be statistically not significant $(\mathrm{p}>0.05)$

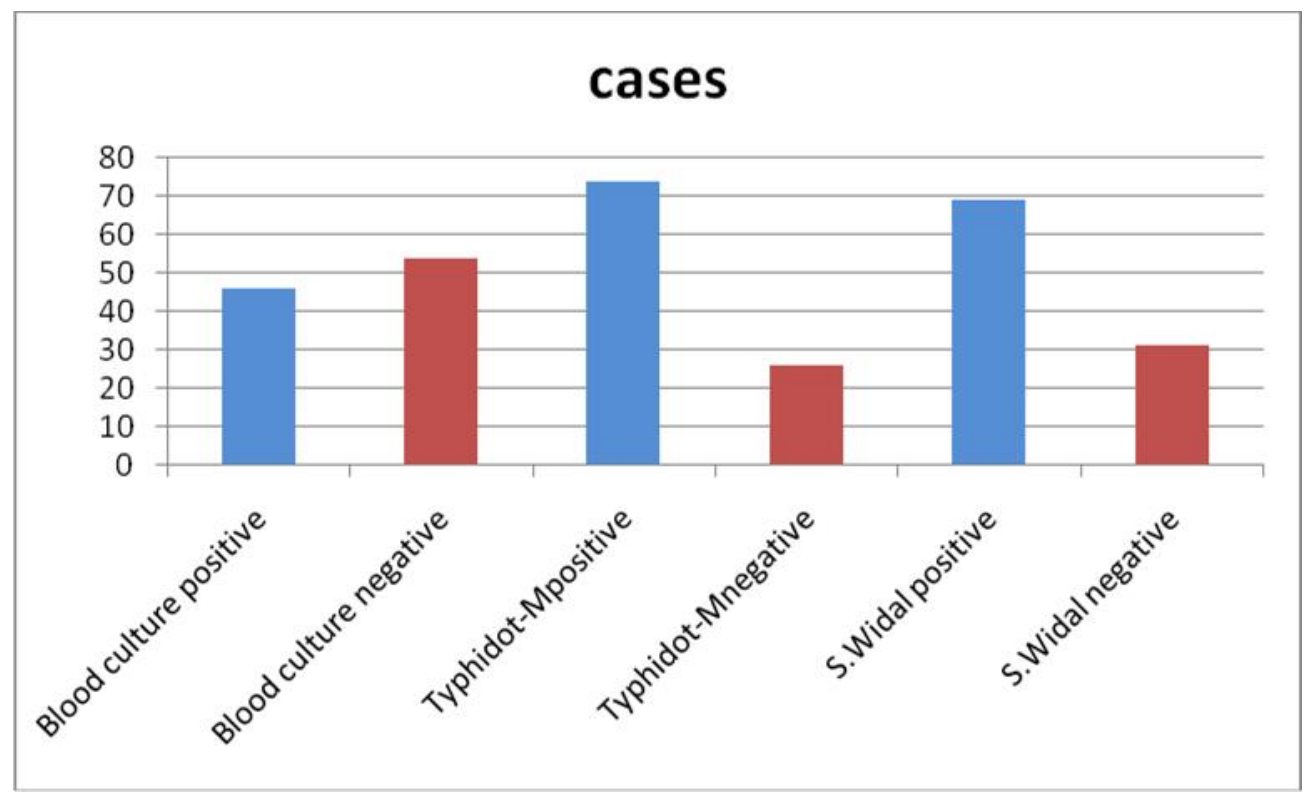

Fig 3. Results in $\%$ of three tests.

Positive cases

Negative cases 
Int. J. Curr. Res. Med. Sci. (2017). 3(3): 83-93

In our study $74 \%$ cases are positive for TyphidotM test followed by $69 \%$ positive for S.Widal test.46\% cases were positive for Blood culture test

Table1. Typhidot-M test and Blood culture test. 2x2 Contingency table and Calculation of S,Sp, PPV,NPV.

\begin{tabular}{|c|c|c|c|c|c|}
\hline & & & \multicolumn{2}{|c|}{ BLOOD CULTURE } & \multirow[b]{2}{*}{ Total } \\
\hline & & & POSITIVE & NEGATIVE & \\
\hline \multirow[t]{8}{*}{ TYPHIDOT-M } & \multirow[t]{4}{*}{ POSITIVE } & \multirow{2}{*}{$\begin{array}{l}\text { Count } \\
\% \text { within TYPHIDOT-M }\end{array}$} & 45 & 29 & 74 \\
\hline & & & $\mathrm{PP}+60.8 \%$ & $39.2 \%$ & $100.0 \%$ \\
\hline & & $\begin{array}{l}\% \text { within } \text { BLOOD } \\
\text { CULTURE }\end{array}$ & $\mathrm{Se}=97.8 \%$ & $53.7 \%$ & $74.0 \%$ \\
\hline & & $\%$ of Total & $45.0 \%$ & $29.0 \%$ & $74.0 \%$ \\
\hline & \multirow[t]{4}{*}{ NEGATIVE } & Count & 1 & 25 & 26 \\
\hline & & $\%$ within TYPHIDOT-M & $3.8 \%$ & NP-96.2\% & $100.0 \%$ \\
\hline & & $\begin{array}{l}\% \quad \text { within } \\
\text { CULTURE }\end{array}$ & $2.2 \%$ & $\mathrm{Sp}=46.3 \%$ & $26.0 \%$ \\
\hline & & $\%$ of Total & $1.0 \%$ & $25.0 \%$ & $26.0 \%$ \\
\hline \multirow[t]{4}{*}{ Total } & & Count & 46 & 54 & 100 \\
\hline & & $\%$ within TYPHIDOT-M & $46.0 \%$ & $54.0 \%$ & $100.0 \%$ \\
\hline & & $\begin{array}{l}\% \text { within } \\
\text { CULTURE }\end{array}$ & $100.0 \%$ & $100.0 \%$ & $100.0 \%$ \\
\hline & & $\%$ of Total & $46.0 \%$ & $54.0 \%$ & $100.0 \%$ \\
\hline
\end{tabular}

Sensitivity(S) of Typhidot-M test $-97.8 \%$

Specificity(Sp) of Typhidot-M test $-46.3 \%$

Positive predictive value(PPV) - $60.8 \%$

Negative predictive value (NPV) - $46.3 \%$

When calculation for $\mathrm{p}$ value was done then we found that $\mathrm{p}$ value is less than 0.001 .So there was significant association between Typhidot-M and Blood culture tests.

Chi-Square Tests

\begin{tabular}{|l|l|l|l|l|l|l|}
\hline & Value & df & $\begin{array}{l}\text { Asymp. Sig. } \\
\text { (2-sided) }\end{array}$ & $\begin{array}{l}\text { Exact Sig. (2- } \\
\text { sided) }\end{array}$ & $\begin{array}{l}\text { Exact Sig. (1- } \\
\text { sided) }\end{array}$ \\
\hline Pearson Chi-Square & $25.134^{\mathrm{a}}$ & 1 & .000 & & \\
Continuity Correction & 22.893 & 1 & .000 & & \\
Likelihood Ratio $^{\text {Fisher's Exact Test }}$ & 30.413 & 1 & .000 & .000 & .000 \\
Linear-by-Linear & 24.883 & 1 & .000 & & & \\
Association & 100 & & & & & \\
N of Valid Cases & & & & & \\
\hline
\end{tabular}

a. 0 cells $(.0 \%)$ have expected count less than 5 . The minimum expected count is 11.96 . 
Int. J. Curr. Res. Med. Sci. (2017). 3(3): 83-93

Chi-Square Tests

\begin{tabular}{|l|l|l|l|l|l|l|}
\hline & Value & $\mathrm{df}$ & $\begin{array}{l}\text { Asymp. Sig. } \\
\text { (2-sided) }\end{array}$ & $\begin{array}{l}\text { Exact Sig. (2- } \\
\text { sided) }\end{array}$ & $\begin{array}{l}\text { Exact Sig. (1- } \\
\text { sided) }\end{array}$ \\
\hline $\begin{array}{l}\text { Pearson Chi-Square } \\
\text { Continuity Correction }\end{array}$ & $25.134^{\mathrm{a}}$ & 1 & .000 & & \\
Likelihood Ratio $^{\text {Fisher's Exact Test }}$ & 22.893 & 1 & .000 & & \\
$\begin{array}{l}\text { Linear-by-Linear } \\
\text { Association } \\
\text { N of Valid Cases }\end{array}$ & 30.413 & 1 & .000 & .000 & .000 \\
\hline
\end{tabular}

a. 0 cells $(.0 \%)$ have expected count less than 5. The minimum expected count is 11.96.

b. Computed only for a $2 \times 2$ table

\section{Symmetric Measures}

\begin{tabular}{|c|c|c|c|c|}
\hline & Value & \begin{tabular}{|lr} 
Asymp. & Std. \\
Error $^{\mathrm{a}}$ &
\end{tabular} & Approx. $\mathrm{T}^{\mathrm{b}}$ & Approx. Sig. \\
\hline $\begin{array}{l}\text { Measure of Agreement Kappa } \\
\mathrm{N} \text { of Valid Cases }\end{array}$ & $\begin{array}{l}.422 \\
100\end{array}$ & .074 & 5.013 & .000 \\
\hline
\end{tabular}

a. Not assuming the null hypothesis.

b. Using the asymptotic standard error assuming the null hypothesis.

Table 2. Calculation of $\mathrm{p}$ value for Typhidot-M test and blood culture(gold standard).

\begin{tabular}{|c|c|c|c|c|c|c|}
\hline & & & & \multicolumn{2}{|c|}{ BLOOD CULTURE } & \multirow[b]{2}{*}{ Total } \\
\hline & & & & POSITIVE & NEGATIVE & \\
\hline \multirow[t]{8}{*}{ S WIDAL } & POSITIVE & Count & & 22 & 47 & 69 \\
\hline & & $\%$ within S WIDAL & & $P P+=31.9 \%$ & $68.1 \%$ & $100.0 \%$ \\
\hline & & $\begin{array}{l}\% \text { within } \\
\text { CULTURE }\end{array}$ & BLOOD & $\mathrm{Se}=\mathbf{4 7 . 8 \%}$ & $87.0 \%$ & $69.0 \%$ \\
\hline & & $\%$ of Total & & $22.0 \%$ & $47.0 \%$ & $69.0 \%$ \\
\hline & NEGATIVE & Count & & 24 & 7 & 31 \\
\hline & & $\%$ within S WIDAL & & $77.4 \%$ & $\mathrm{NP}-=22.6 \%$ & $100.0 \%$ \\
\hline & & $\begin{array}{l}\% \quad \text { within } \\
\text { CULTURE }\end{array}$ & BLOOD & $52.2 \%$ & $\mathrm{Sp}=13.0 \%$ & $31.0 \%$ \\
\hline & & $\%$ of Total & & $24.0 \%$ & $7.0 \%$ & $31.0 \%$ \\
\hline \multirow[t]{4}{*}{ Total } & & Count & & 46 & 54 & 100 \\
\hline & & $\%$ within S WIDAL & & $46.0 \%$ & $54.0 \%$ & $100.0 \%$ \\
\hline & & $\begin{array}{l}\% \quad \text { within } \\
\text { CULTURE }\end{array}$ & BLOOD & $100.0 \%$ & $100.0 \%$ & $100.0 \%$ \\
\hline & & $\%$ of Total & & $46.0 \%$ & $54.0 \%$ & $100.0 \%$ \\
\hline
\end{tabular}

Table 3. Widal and Blood culture test $2 \times 2$ Contingency table 
Sensitivity of S.Widal test $\quad-47.8 \%$

Specificity of S.Widal test - $13 \%$

Positive predictive value $\quad-39.1 \%$

Negative predictive value $\quad-\quad 22.6 \%$

\begin{tabular}{|c|c|c|c|c|c|}
\hline & Value & df & \begin{tabular}{|l} 
Asymp. \\
Sig. \\
sided $)$
\end{tabular} & \begin{tabular}{|l} 
Exact \\
Sig. \\
sided $)$
\end{tabular} & $\begin{array}{l}\text { Exact } \\
\text { Sig. } \\
\text { sided })\end{array}$ \\
\hline Pearson Chi-Square & $\mid \begin{array}{l}17.85 \\
5^{\mathrm{a}}\end{array}$ & 1 & .000 & & \\
\hline Continuity Correction $^{b}$ & $\begin{array}{l}16.06 \\
9\end{array}$ & 1 & .000 & & \\
\hline Likelihood Ratio & $\begin{array}{l}18.48 \\
4\end{array}$ & 1 & .000 & & \\
\hline Fisher's Exact Test & & & & .000 & .000 \\
\hline Linear-by-Linear Association & $\begin{array}{l}17.67 \\
6\end{array}$ & 1 & .000 & & \\
\hline $\mathrm{N}$ of Valid Cases ${ }^{\mathrm{b}}$ & 100 & & & & \\
\hline
\end{tabular}

a. 0 cells $(.0 \%)$ have expected count less than 5 .

The minimum expected count is 14.26 .

b. Computed only for a $2 \times 2$ table

Sensitivity of S.Widal test $\quad-47.8 \%$

Specificity of S.Widal test $\quad-13 \%$

Positive predictive value $\quad-39.1 \%$

Negative predictive value $\quad-\quad 22.6 \%$

\section{Symmetric Measures}

\begin{tabular}{|l|l|l|l|l|}
\hline & Value & $\begin{array}{l}\text { Asymp. Std. } \\
\text { Error }^{\mathrm{a}}\end{array}$ & Approx. T & Approx. Sig. \\
\hline $\begin{array}{l}\text { Measure of Agreement Kappa } \\
\text { N of Valid Cases }\end{array}$ & -.378 & .087 & -4.225 & .000 \\
\hline
\end{tabular}

a. Not assuming the null hypothesis.

b. Using the asymptotic standard error assuming the null hypothesis.

Table 4. Calculation of $\mathrm{p}$ value for S.Widal test and Blood culture (gold standard).

When calculation for $\mathrm{p}$ value is done then we found that $\mathrm{p}$ value $<0.001$, So there is significant association between S.Widal and Blood culture tests.

Comparison of sensitivity and specificity, PPV and NPV of Typhidot-M and S.Widal test shows that Typhidot-M test has better results.

\section{Discussion}

This study was carried out to study the Rapid diagnostic test Typhidot-M.We calculated sensitivity, specificity, positive predictive and negative predictive value of Typhidot-M and S.Widal test by keeping blood culture positive cases as gold standard.

The sensitivity and specificity of Typhidot-M test were $97.8 \%$ and 46.3\%.Positive and Negative predictive values were $60.8 \%$ and $96.2 \%$.p value for Typhidot-M test was $<0.001$ ie. highly significant statistically.

The sensitivity and specificity of S.Widal test were $47.8 \%$ and 13\%.Positive and Negative 
predictive values were $31 \%$ and $22.6 \%$. p value for S.Widal test was $<0.001$ ie. significant statistically.Typhidot-M test was evaluated by other workers who also found that this test is superior to Widal test in sensitivity and specificity.

Table 5. Comparison of our result with various studies done for evaluation of Typhidot-M test.

\begin{tabular}{|c|c|c|c|c|c|c|}
\hline Author & Year of study & Test & $S$ & $\mathrm{Sp}$ & PPV & NPV \\
\hline Our Result & 2012 & Typhidot-M & 97.8 & 46.3 & 60.8 & 96.2 \\
\hline Choo et al. ${ }^{25}$ & 1994 Malasia & Typhidot & 95 & 75 & & 96 \\
\hline Bhutta et al $^{19}$ & 1999 karachi & Tyhidot-M & 94 & 77 & 88 & 87 \\
\hline Jesudason et al $^{17}$ & 2002-2003 Vellore & Typhidot & 92.3 & 98.8 & 85.7 & 99.4 \\
\hline Oslen et al18 & 2000-2002Vietnam & Typhidot & 79 & 89 & 96 & 59 \\
\hline D Narayanapa et al ${ }^{11}$ & 2008Mysore & TyphidotM & 92.6 & 37.5 & 48.7 & 88.8 \\
\hline Beig et $\mathrm{al}^{23}$ & 2010 Aligarh & Typhidot-M & 90 & 100 & 100 & 92.1 \\
\hline
\end{tabular}

Various studies which had evaluated typhidot-M test showed sensitivity and specificity which ranged from $47-94 \%$ and $37.5-100 \%$ as shown in the above chart. In our study the sensitivity and specificity of Typhidot-M is $97.8 \%$ and $46.3 \%$ with PPV- 60.8 and NPV 96.2, which is comparable to the studies done by Bhutta et al, Narayanappa et al and Beig et al. Typhidot-M meets one of the criteria of an ideal diagnostic test as it usually doesn't miss the diagnosis when compared to blood culture.Only one case which was positive for blood culture was negative for Typhidot-M Test in our study.This patient had fever duration of more than 10 days .Probably decreasing levels of IgM against outer membrane protein of cell wall and masking of IgM by IgG in the 2nd week may be the reason for Typhidot-M negativity. There were 29 cases which were apparently false positive by Typhidot-M out of 54 blood culture negative cases. As Typhidot-M test detects IgM antibodies in 2nd week when blood culture positivity declines thus more cases were picked up by this test when duration of fever was more . Out of 46 blood culture positive cases, Typhidot-M test was positive in $97.8 \%$ and Widal test was positive in $47.8 \%$. In our study Sensitivity and Specificity of S.Widal test were $47.8 \%$ and $13 \%$.Positive predictive value and Negative predictive values were $31.9 \%$ and 22.6\%. Comparison of sensitivity and specificity, PPV and NPV of Typhidot-M and S.Widal test shows that Typhidot-M test had better results. Thus Typhidot-M was significantly more sensitive than the Widal test, although the sensitivity and specificity of S.Widal test were lower than the other studies. ${ }^{22-25}$ In contrast to findings from other parts of Asia, ${ }^{27,28}$ our data support the contention that the Widal test had poor diagnostic value in children with typhoid fever. ${ }^{29,30}$ This indicates that Typhidot-M test can also be effectively used for early diagnosis of typhoid fever as also reported earlier. It is optimal to evaluate the rising IgM titers as these titers rise during early phase of typhoid fever. Hence it is recommended to do this test for the early diagnosis and appropriate treatment of typhoid fever. This test does not require special equipment and technical training of staff but the instructions are to be stringently followed. It uses a small volume of serum and the result can be interpreted in an hour. Blood culture was positive in $46 \%$ of cases which is comparable to other studies by Bhutta et al ${ }^{19}$, Dheer et al ${ }^{26}$, Mishra et al ${ }^{31}$ and this may be attributable to the difficulties of obtaining large enough blood volumes for cultures from children and it is a low bacteremic illness.

It must be emphasized that although cultures are associated with a lag period of at least $48 \mathrm{hr}$ for preliminary confirmation of infection, with the recent emergence of drug resistance among $\mathrm{S}$. typhi, they remain an essential investigation. In many circumstances, especially among partially treated cases presenting to health facilities, combining cultures with a rapid serologic test may reduce the diagnostic difficulty in typhoid fever. Our data indicates that combining the blood culture with a Typhidot-M test will significantly improve the diagnostic yield of these 
investigations among children. We do not believe that our data support the use of either the Widal or Typhidot tests as a substitute for cultures in typhoid fever. The Typhidot-M offers an additional advantage among second- line serologic diagnostic tests for typhoid fever in that the test strips do not require an ELISA reader for evaluation. Also, only minimal operator training is required. Nevertheless, the 3-4-fold higher cost of the test in comparison with the Widal test, as well as cold-storage requirements for test strips, are additional impediments in using this test in developing countries.

\section{Conclusion}

To Conclude: Typhidot -M test helps to identify cases of typhoid fever at the earliest before the other test results like s.widal test and blood culture are available. Thus it can prove to be of help in early diagnosis of typhoid fever which further will help in early institution of antibiotics for its treatment.

\section{References}

1. Cleary TG, Salmonella. In: Behrman RE, Kliegman RM, Jenson H. Nelson Textbook of Pediatrics, 19th Edition. Philadelphia: Saunders Publishers; 2004. P. 954-958.

2. WainJ,DiepTS,Hova,WalshAM,NguyenTT ,ParryCM,WhiteNJ(1998).Quantification of bacteria in blood of typhoid fever patients and relationship between counts and clinical features,transmissibility and antibiotic resistance. J. Clin. Microbiol, 36:1683-87.

3. Rapid Diagnosis of Typhoid Fever. Indian J Med Res 123, April 2006, 489-492.

4. Jog S, Soman R, Singhal T, Rodrigues C, Mehta A, Dastur FD.Enteric fever in Mumbai - clinical profile, sensitivity patterns and response to antimicrobials. JAPI 2008; 56:237-40

5. Sinha A, Sazawal S, Kumar R, et al. Typhoid fever in children aged less that 5 years. Lancet 1999; 354:734-7.

6. Jesudason $\mathrm{M}$, Esther $\mathrm{E}$, Mathai $\mathrm{E}$. Typhidot test to detect $\operatorname{IgG}$ and $\operatorname{IgM}$ antibodies in typhoid fever. Indian $\mathrm{J}$ Med Res 2002: 116; 70-72.
7. Farooqui BJ, Khurshid M, Ashfaq MK, Khan MA. Comparative yield of Salmonella typhi from blood and bone marrow cultures in patients with fever of unknown origin.J Clin Pathol 1991; 44: 258-259.

8. WidalF (1896).Serodignosis de la fievere typhoid.Semaine Med.16:259.

9. Olopoenia LA, King A. Widal Agglutination Test -100 Years Later: Still plagued by controversy. Postgrad Med J 2000; 76: 80-84.

10. Parry Cm, Hoa NT, Diep TS, Wain J, Chinh NT, Vinh H, et al. Value of a single tube Widal test in diagnosis of typhoid fever in Vietnam. J Clin Microbiol 1999; 37: 2882-2886.

11. D Narayanappa, Rachana sripathi, K Jagdishkumar and HS Rajani. Comparative study of dot enzyme immunoassay (Typhidot-M) and Widal test in the diagnosis of typhoid fever. Indian pediatrics 2010; 47:331-333.

12. Nsutebu EF, Ndumbe PM, Shiro K. The increase in occurrence of typhoid fever in Cameroon: overdiagnosis due to misuse of the Widal test? Trans R Soc Trop Med Hyg 2002; 96: 64-67.

13. Akoh JA. Relative sensitivity of blood and bone marrow cultures in typhoid fever.Trop Doct 1991; 21: 174-176.

14. . Ismail A, Kader SA, Ong KH. Dot enzyme immunosorbent assay for the serodiagnosis of typhoid fever. Southeast Asian J Trop Med Pub Health 1991; 22:563-6.

15. Olsen SJ, Pruckler J, Bibb W, Thanh NTM, Trinh TM, Minh NT, et al. Evaluation of rapid diagnostic tests for typhoid fever. J Clin Microbiol 2004; 42:1885-9.

16. Ashcroft Mt. Typhoid and paratyphoid fevers in the tropics. J Trop Med Hyg. 1964; 67:185-189.

17. Jesudason $\mathrm{M}$, Esther E, Mathai E. Typhidot test to detect $\operatorname{IgG} \&$ IgM antibodies in typhoid fever. Indian J Med Res 2002; 116:70-72.

18. Olsen SJ, Pruckler J, Bibb W, Thanh NTM, Trinh TM, Minh NT, et al. Evaluation of rapid diagnostic tests for 
typhoid fever. J Clin Microbiol 2004; 42:1885-9.

19. Bhutta ZA, Mansurali N. Rapid serologic diagnosis of pediatric typhoid fever in an endemic area: A prospective comparative evaluation of two dot-enzyme immunoassays and the Widal test. Am J Trop Med Hyg 1999; 61: 654-657.

20. Jackson AA, Ismail A, Ibrahim TA, Kader ZS, Nawi NM. Retrospective review of dot enzyme immunoassay test for typhoid fever in an endemic area. Southeast Asian J Trop Med Pub Hlth 1995; 26: 625-630.

21. $\mathrm{WHO} / \mathrm{V} \& \mathrm{~B} / 03.07$.The diagnosis treatment and prevention of typhoid fever.

22. BegumZ,HossainMA,MusaAK,Shamsuzza manAK,MahmudMC,AhsanMM,SumonaA A,AhmedS,JahanNA,AlamM,BegumA.Co mparison between DOT EIA IgM and Widal Test as early diagnosis of typhoid fever.Mymensingh

Med J,2009Jan;18(1):13-7.

23. BeigFK,AhmadF,EkramM,ShuklaI.Typhid otMand Diazo test vis-a vis blood culture and Widal test in early diagnosis of typhoid fever in a resource poor setting.Braz $\mathbf{J}$ Infect Dis .2010Dec;14(6):589-93.

24. Khoharo. A comparative study of the typhidot (Dot-EIA)and Widal tests in blood culture positive cases of typhoid fever.Trop Doct.2011May16.
25. Choo KE, Oppenheimer SJ, Ismail AB, Ong KH, 1994. Rapid serodiagnosis of typhoid fever by dot enzyme immunoassay in an endemic area. Clin Infect Dis 19: 172-176.

26. DheerG, KundraS, SinghS.Clinical and laboratory profile of enteric fever in children in northern India. Tropical doctor 2012:1-3.

27. Chow C-B, Wang P-S, Cheung M-W, Yan W-W, Leung N-K, 1987. Diagnostic value of the Widal test in childhood typhoid fever. Pediatr Infect Dis J 6: 914-917.

28. Rasaily R, Dutta P, Saha MR, Mitra U, Bhattacharya SK, Manna B, Mukherjee A, Chakravorty S, Pal SC, 1993. Value of a single Widal test in the diagnosis of typhoid fever. Indian J Med Res 97: 104107.

29. Saha SK, Ruhulamin M, Hanif M, Islam M, Khan WA, 1996. Interpretation of the Widal test in the diagnosis of typhoid fever in Bangladeshi children. Ann Trop Paediatr 16: 75-78.

30. Onuigbo MAC, 1990. Diagnosis of typhoid fever in Nigeria: misuse of the Widal test. Trans R Soc Trop Med Hyg 84: 129-131.

31. Mishra.S, PatwariAK, AnandVK, PillaiPK, AnejaS, ChandraJ, SharmaD. A clinical profile of multidrug resistant typhoid fever. Indian Paediatrics, Vol 28.Oct1991,117174.

\begin{tabular}{|c|c|}
\hline \multicolumn{2}{|c|}{ Access this Article in Online } \\
\hline \multirow{2}{*}{ 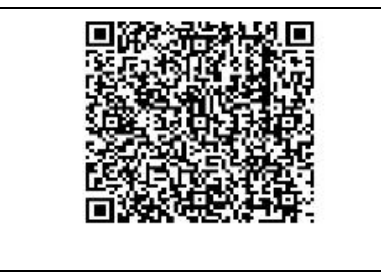 } & $\begin{array}{l}\text { Website: } \\
\text { www.ijcrims.com }\end{array}$ \\
\hline & $\begin{array}{l}\text { Subject: } \\
\text { Pediatrics }\end{array}$ \\
\hline Quick Response Code & \\
\hline
\end{tabular}

How to cite this article:

Neeraj Lata, Vijay Gotwal,. Tanushree Joshi,YogeshGupta, D P Pande, Dr BrahmPrakash. (2017). Cross sectional study to evaluate rapid diagnostic test (Typhidot-M) as a tool for early diagnosis of Typhoid fever keeping blood culture as gold standard. Int. J. Curr. Res. Med. Sci. 3(3): 83-93.

DOI: http://dx.doi.org/10.22192/ijcrms.2017.03.03.011 